\title{
The Nature of STEM Disciplines in the Science Education Standards Documents from the USA, Korea and Taiwan
}

\section{Focusing on Disciplinary Aims, Values and Practices}

\author{
Wonyong Park ${ }^{1}$ (D) Jen-Yi Wu ${ }^{1} \cdot$ Sibel Erduran $^{1,2}$
}

Published online: 7 July 2020

(C) The Author(s) 2020

\begin{abstract}
Understanding the nature of science (NOS) has emerged as a core curricular goal since at least the 1960s. While science education reforms around the world have shed light on various epistemic and social underpinnings of science, how science curriculum documents portray the nature of other related disciplines such as mathematics and engineering has drawn little attention. Such lack of attention is surprising, given the growing interest among educators in the integrated approach to science, technology, engineering and mathematics (STEM) education and the frequent emphasis on STEM in recent curriculum policy. The study reported in this paper aimed to understand how recent science education reform documents from the USA, Korea and Taiwan compare with regard to their representation of the nature of STEM disciplines. Using the framework of the family resemblance approach (FRA), we present a comparative analysis of three recent science education standards documents to examine their coverage of the epistemic underpinnings of STEM disciplines, particularly with regard to the disciplinary aims, values and practices. The results indicate that the features specific to science and shared by science and engineering were most frequently addressed in the standards documents, whereas mathematics-related features were rarely mentioned. Furthermore, there was variation in the coverage in terms of the nature of STEM disciplines. Based on the findings, we discuss the contributions of the FRA framework in analysing STEM curricula in an interdisciplinary manner and make suggestions for integrating the nature of STEM disciplines in science curriculum documents.
\end{abstract}

Wonyong Park

wonyong.park@education.ox.ac.uk

1 Department of Education, University of Oxford, 15 Norham Gardens, Oxford OX2 6PY, UK

2 The Norwegian Centre for Science Education, University of Oslo, Oslo, Norway 


\section{Introduction}

Science, technology, engineering and mathematics (STEM) education and nature of science (NOS) are among the most significant themes that drive science education research and practice today, as evidenced by multiple reviews of research trends (Lee et al. 2009; Lin et al. 2018; Lin et al. 2014). From a curriculum point of view, STEM and NOS can both be viewed as extensions of what should be taught in school science, in the sense that they are both efforts to transcend the traditional content-oriented science curriculum that often fails to capture and to teach authentic scientific practices. Approaches in STEM education attempt to achieve such goals by integrating neighbouring disciplines (technology, engineering and mathematics) into the science curriculum, whereas NOS does so by bringing ideas from the meta-scientific, humanistic and social investigations of the scientific enterprise such as history, philosophy, sociology and anthropology of science.

Science educators' long-standing interest in NOS has led to a series of studies that analysed the NOS content of science curricula in different countries. McComas and Olson's (2002) early review of international science education standards documents demonstrated that there were certain aspects of NOS commonly addressed in the standards, and the documents included a range of issues across the philosophy, history, sociology and psychology of science. Published 16 years later, Olson's (2018) analysis of nine international standards documents provided the disconcerting result that NOS still appears more frequently in the supplementary materials than as explicit learning expectations, indicating that the standards documents lag behind the research on NOS that have stressed an explicit and reflective approach. Similar observation was reported in a recent historical review of NOS representations in the 98 US science education standards documents by Summers et al. (2019). Their analysis revealed that the documents' coverage of NOS had little improved over the 30 years, suggesting that there may be a gap between advances in research on NOS and incorporation of research in curriculum policy.

Building on the body of research on NOS, this article investigates how science curriculum documents portray the nature of science, technology, engineering and mathematics. Here, the question arises: Why is it important to consider the nature of other disciplines as represented in science curricula rather than just NOS? One apparent reason is that scientific practice, whether in the past or present, is inherently interdisciplinary and reliant upon other disciplines. Hence, understanding NOS cannot be separated from understanding the features of technology, engineering and mathematics and how they relate to each other (AAAS 1989; Honey et al. 2014). A rich volume of literature in science studies (i.e. history, philosophy and sociology of science) has demonstrated that scientific practice is inseparable from the practice of technology, engineering and mathematics. Such interdependence is evidenced in many examples that show how technological innovations yield new possibilities in science (e.g. Pitt 2000; Price 1984), how science and mathematics are interdependent in the advancement of knowledge (e.g. Forinash et al. 2000), and how the border between science and engineering is blurred in real contexts (e.g. Janich 1978). Another rationale for directing attention to the nature of STEM disciplines ${ }^{1}$ comes from the fact that many core goals of science education

\footnotetext{
${ }_{1}$ Throughout the paper, we use the term 'nature of STEM disciplines' to collectively refer to NOS, NOT, NOE and NOM. This should be distinguished from what could be called 'nature of STEM', in that the latter would consider 'STEM' as a single discipline and refer to what features it entails. Although this distinction would be an interesting topic that merits separate discussion, for the purpose of this paper, we refer to "nature of STEM disciplines', not 'nature of STEM'.
} 
today cannot be achieved without contributions from other disciplines. Moreover, relatively new components of scientific literacy, such as the understanding of science and engineering practices, computational thinking and systems thinking, involve cross-disciplinary skills and competencies, blurring the boundaries between NOS and the nature of other disciplines. Therefore, aligning these goals of science education with NOS mandates an integrated approach in order to avoid a partial and incomplete understanding of NOS.

For these reasons, investigating the nature of STEM disciplines is of critical importance, both in the STEM and NOS education contexts. While STEM education and NOS have both drawn significant attention within the science education community (Lin et al. 2018), there have been few attempts to investigate the intersection of these two research domains. In this paper, our task is to compare the three recent science education standards from the USA, Korea and Taiwan, especially their coverage of the nature of STEM disciplines. In so doing, the purpose of the comparative analysis is twofold: first, to contrast the relative coverage and characteristics of the three documents examining the implications for each country and, second, based on this analysis, to explore the opportunities and challenges of extending NOS frameworks to the nature of STEM disciplines at an international level. The research question that guided the empirical data analysis was: How do recent science curriculum standards documents from USA, Korea and Taiwan address the nature of STEM disciplines with regard to disciplinary aims, values and practices?

\section{Theoretical Background}

\subsection{Integrated STEM}

STEM education is 'a standards-based, meta-discipline residing at the school level where all teachers, especially science, technology, engineering, and mathematics (STEM) teachers, teach an integrated approach to teaching and learning, where discipline-specific content is not divided, but addressed and treated as one dynamic, fluid study' (Merrill 2009, p. 1). While there is no single definition of STEM education that is widely agreed upon in both theory and practice (Bybee 2013; Martín-Páez et al. 2019; Wong et al. 2016), the common usage of the term today tends to involve a sense of the integration of the four constituent disciplines in various ways and levels rather than treatment of them as disciplines isolated from one another (Bybee 2013; Honey et al. 2014; STEM Task Force Report 2014). Within the science education community, STEM integration has gained sustained momentum since the inclusion of technology- and engineering-related standards in Science for All Americans (AAAS 1989), Benchmarks for Science Literacy (AAAS 1993) and the National Science Education Standards (NRC 1996). The recent release of the US Next Generation Science Standards (NGSS; NGSS Lead States 2013), which introduced engineering practices as a key component of the science curriculum, has sparked science educators' interest in the intersection of science and engineering. For example, Duschl and Bismack (2016) capitalised on common practices across the STEM disciplines such as 'systems thinking', 'model-based reasoning' and 'quantitative reasoning'. Similarly, Engelmann, Chin, Osborne and Fischer (2018) extensively addressed the issue of discipline-general and discipline-specific aspects of scientific reasoning and argumentation.

It has been pointed out that the early motivation for integrated STEM education was primarily state-led economic imperatives, on the grounds that skills and literacy in STEM 
disciplines would be essential for the workforce to sustain economic growth of a country (Charette 2014; Williams 2011; Wong et al. 2016). The following statement from the report of the US Committee on Integrated STEM Education, for example, emphasises the needs of employers and industries as a key motivation for promoting STEM education for students:

a second factor driving interest in integrated STEM education: concern about how to better prepare U.S. students to enter the workplace, whether immediately after high school or following postsecondary coursework. An increasing share of jobs across a range of economic sectors, not just in science and engineering, is likely to require some background in the STEM subjects (Carnevale et al. 2011). In addition, employers have made clear their need for workers who can flexibly apply knowledge to solve practical problems (AACU 2013). (Honey et al. 2014, p. 136)

More recently, arguments have been put forward to refocus the aims of STEM education from pursuing economic profits to responding to the fundamental challenges that humanity is faced with. Chesky and Wolfmeyer (2015), for example, criticised the idea of STEM education rooted in the profit-driven consumerism and called for recognising the STEM's potential for fostering social and environmental justice and aesthetic and democratic values. Similarly, Bybee (2013) stressed understanding the "characteristic features of STEM disciplines as forms of human knowledge, inquiry and design' and 'awareness of how STEM disciplines shape our material, intellectual and cultural environments' (p. xi) as elements of what he calls 'STEM literacy', a general aim of STEM education. Zeidler (2016) called for explicit attention to socio-scientific and socio-cultural issues that can make STEM relevant to important issues that matter in human lives. He argued that educators should aim to inform the public in order to able to exercise prudence, morality and character. In so doing, Zeidler advocates framing STEM topics in the broader social, cultural and political contexts - which he called 'humanistic contributions' of STEM education (Zeidler 2016). Authors such as Chesky and Wolfmeyer (2015) and Zeidler (2016) share the position that the purpose of teaching STEM subjects cannot be reduced to fulfilling the economic needs of society but should involve the general aims of educating democratic citizens and promoting social justice. Such themes resonate with recent arguments on the rationale for inclusion of NOS in science education (Yacoubian and Hansson in press).

\subsection{Nature of STEM Disciplines in Science Curriculum Documents}

While the significance of understanding NOS in achieving scientific literacy has been well established and shared among science educators, mismatch has been reported between research findings and the curriculum policy regarding NOS. One example of such a mismatch is that while many science curriculum documents around the globe describe NOS as their generic and higher-level goal, they tend not to identify it as an explicit and cognitive learning outcome (McComas and Olson 2002; Olson 2018). Given that rich empirical evidence supports teaching NOS as a cognitive and epistemic learning (Abd-El-khalick and Lederman 2000; Akerson et al. 2000) including NOS in state-level science education standards and curriculum documents is essential. Moreover, the observation that science teachers' coverage of NOS in their classroom practices and instructional approaches requires strong reliance on curriculum materials (Chiappetta et al. 2006; Summers et al. 2019) also supports these documents being more explicit and systematic in addressing the content and pedagogy of NOS. 
At this point, it is worthwhile to pause to address the question of what we mean by 'nature' of STEM disciplines when we talk about nature of science (NOS), nature of technology (NOT), nature of engineering (NOE) and nature of mathematics (NOM). There is no clear-cut answer to this question, since different researchers conceptualised NOS itself from different perspectives (see Dagher and Erduran 2017 for different coverage of NOS across science education researchers). Some researchers have focused on several salient characteristics of science that are agreed upon (e.g. Lederman et al. 2002; McComas et al. 1998), whereas others have proposed NOS frameworks that embrace a wider range of aspects in various sciences bearing in mind the complexities of disagreements among scientists (Allchin 2016; Dagher and Erduran 2017; Hodson and Wong 2017). Although a comprehensive discussion on this issue exceeds the scope of the current paper, it would be useful at least to clarify our use of 'nature' that applies to each of the STEM disciplines. In this paper, following Irzik and Nola (2014), we use 'nature' to refer to a set of 'family resemblances'. For example, what counts as 'nature' of technology is some aspects of technology (e.g. epistemic aims, methods of inference, use of modelling) that can be compared or contrasted with those of other disciplines such as engineering. This way of defining 'nature' allows us to understand NOS, NOT, NOE and NOM as interrelated and mutually defining rather than something that exists independently of each other. There are of course also disciplinary differences and nuances which are also captured by the family resemblance idea by its very definition (for an extended discussion of how the domain-general and domain-specific aspects of family resemblance see Erduran and Dagher 2014a, b).

Despite the abundance of research on the representation of NOS in curriculum documents, one of the issues remaining relatively uncharted is how NOS could be linked to the nature of other closely related subjects such as technology, engineering and mathematics. For example, although nature of technology (NOT) and nature of engineering (NOE) started to appear in the literature in the 1990s, it has only been recently that their importance in the K-12 science curriculum has been highlighted in the science education research literature (Kaya et al. 2018; Pleasants and Olson 2018). Antink-Meyer and Brown (2019) recently proposed a NOE framework for K-12 science instruction that consists of seven features: Engineering is solution-oriented, contextually responsive, empirically based, influenced by societal and cultural factors, a social process, and interdisciplinary and has a personal dimension. It is important that Antink-Meyer and Brown examined these features of engineering in relation to the NOS rather than treating them as something disconnected from NOS. Chesky and Wolfmeyer's (2015) recent study on the philosophical aspects of STEM is an interesting case, in that it was conducted by mathematics educators. Using a framework based on Badiou's set theory method of analysis, they analysed 38 documents about the US STEM education on what axiological, ontological and epistemological stances are represented and how these stances are interrelated in the documents. While a handful of studies including the above examples have begun to address the relevance of NOT and NOE to the science curriculum, there is still limited research on nature of mathematics (NOM) in studies on NOS in the science education literature.

It is now widely recognised that science, technology, engineering and mathematics are interrelated and reliant on each other. They share many features as disciplines, which is perhaps one of the main reasons that they are referred to together as STEM. For example, Science for All Americans (AAAS 1989) includes a very comprehensive description of the interrelation of mathematics with both science and technology: 
Mathematics and science have many features in common. These include a belief in understandable order; an interplay of imagination and rigourous logic; ideals of honesty and openness; the critical importance of peer criticism; the value placed on being the first to make a key discovery; being international in scope; and even, with the development of powerful electronic computers, being able to use technology to open up new fields of investigation.

Mathematics and technology have also developed a fruitful relationship with each other. The mathematics of connections and logical chains, for example, has contributed greatly to the design of computer hardware and programming techniques. Mathematics also contributes more generally to engineering, as in describing complex systems whose behaviour can then be simulated by computer. In those simulations, design features and operating conditions can be varied as a means of finding optimum designs. For its part, computer technology has opened up whole new areas in mathematics, even in the very nature of proof, and it also continues to help solve previously daunting problems. (p. 18)

Similarly, A Framework for K-12 Science Education (NRC 2012) has an explicit statement on the interdependence of science and technology, a core idea which was succeeded by NGSS:

New insights from science often catalyse the emergence of new technologies and their applications, which are developed using engineering design. In turn, new technologies open opportunities for new scientific investigations. (NRC 2012, p. 210)

The proximity of disciplines, however, does not necessarily mean that these disciplines have the same sets of epistemic and non-epistemic characteristics. For example, when it comes to epistemic aims and values, scientists usually pursue explanations of natural phenomena, whereas engineers tend to seek practical and functional values (e.g. Gendron 1977; Kroes 2012; Pacey 1983). On the other hand, mathematics is often understood as purely logical and non-empirical, which distinguishes it from the other three disciplines that are empirically based. Although there often are complex circumstances that raise questions about such simplistic divides, the diversity across STEM disciplines point to the need for an approach that can properly reflect their similarities, differences and connections, which have rarely been addressed in the literature (Honey et al. 2014).

In this article, we focus on the nature of STEM as reflected in the science education standards documents published recently in three countries: USA, Korea and Taiwan. Science education standards documents 'represent a group's best effort to find consensus about the essential concepts to be learned within scientific subdisciplines' (Haag and Megowan 2015, p. 417). At the same time, standards documents guide the textbook writing and teaching of both science content knowledge and NOS in classrooms (Summers et al. 2019). Wilson and Bertenthal (2005) argued that standards documents guide 'the development of curriculum, the selection of instructional resources, and the choices of teachers in setting instructional priorities and planning lessons and function as the basis for developing assessments, setting performance levels, and judging student and school performance' (p. 54). For example, since NGSS was published in 2013, it has led to numerous NGSS-aligned curricula, teaching materials, assessments and teacher education programmes, not to mention the science education research efforts informed by NGSS (e.g. Lederman and Lederman 2017; Sadler and Brown 2018). Analysing curriculum standards documents can thus provide useful insights for the future direction of the integration of STEM in different parts of the world. 


\section{Conceptual Framework: Family Resemblance Approach to NOS}

Since NOS became an agenda for science education researchers and curriculum designers, one major concern has been making decisions on what NOS content should be taught to students. This concern is analogous to asking how we conceptualise the scientific enterprise in the context of school science. A classical approach to this problem has been to compile a list of the characteristics of science on which a certain degree of consensus could be formed among historians, philosophers and sociologists of science. Referred as the 'consensus view' (or the 'general aspects view') of science, this view has informed numerous studies on NOS during the past two decades. The consensus approach includes the empirical, inferential, creative, theory-laden and tentative nature of science, along with the myth of 'the scientific method', the distinction between theories and laws, the social dimensions of science, and the social and cultural embeddedness of science (Abd-El-Khalick et al. 2008; Lederman 2007).

More recent perspectives on NOS tend to highlight the diversity, plurality and domainspecificity that are present in the scientific practice (Allchin 2017; Erduran and Dagher 2014a, b; Hodson and Wong 2017; Irzik and Nola 2011; Matthews 2012). What these authors emphasise in common is a view that the dissimilarities among diverse sciences are as important as their similarities in characterising science (Hodson 2014). Hodson (2014) made a convincing case that a large portion of the current representation of science in curricula and textbooks comes from physics, which resulted in the diverse practices in other sciences such as biology and geosciences being underrepresented. Similarly, there has been increasing awareness among NOS scholars that there is no single scientific method applicable across scientific domains: Not all sciences aim to test hypotheses using controlled experiments, and not all sciences interact with society in the same manner (Matthews 2012; Park and Song 2019).

FRA is an attempt to tackle these issues in NOS by drawing on the concept of 'family resemblance', which can be traced back to the early twentieth century philosopher Ludwig Wittgenstein's work. Consider the concept 'game': What are the essential conditions that are both necessary and sufficient to characterise the activities called 'game'? Wittgenstein noted that it is impossible to find 'what is common to all these activities and what makes them into language or parts of language' (Wittgenstein 1953/2009, p. 35), because not all games follow rules, are competitive or have winners and losers. Instead, concepts such as game are characterised based on the similarities between its instances and 'a complicated network of similarities overlapping and criss-crossing' (p. 36). He suggests the resemblance between family members as a more accurate analogy and concludes:

I can think of no better expression to characterise these similarities than 'family resemblances'; for the various resemblances between members of a family-build, features, colour of eyes, gait, temperament, and so on and and so forth-overlap and criss-cross in the same way-And I shall say: 'games' form a family. (p. 36)

In the 2010s, Irzik and Nola elaborated upon Wittgenstein's notion of family resemblance to explain the nature of 'science'. On their account, science can be better understood by broadly distinguishing it into its 'cognitive-epistemic' and 'social' dimensions, each comprising several sub-elements listed in the following description:

Science is a cognitive and social system whose investigative activities have a number of aims that it tries to achieve with the help of its methodologies, methodological rules, system of knowledge certification and dissemination in line with its institutional social- 
Table 1 Descriptions of FRA categories in the context of STEM (Park et al. in press)

\begin{tabular}{|c|c|}
\hline Category & Description \\
\hline Aims and values & $\begin{array}{l}\text { The key cognitive and epistemic objectives of STEM, such } \\
\text { as accuracy and objectivity }\end{array}$ \\
\hline Methods & $\begin{array}{l}\text { The manipulative and non-manipulative techniques that } \\
\text { underpin STEM research }\end{array}$ \\
\hline Practices & $\begin{array}{l}\text { The set of epistemic and cognitive practices that lead to STEM } \\
\text { knowledge through social certification }\end{array}$ \\
\hline Knowledge & $\begin{array}{l}\text { Theories, laws and explanations that underpin the outcomes } \\
\text { of STEM inquiry }\end{array}$ \\
\hline $\begin{array}{l}\text { Social certification } \\
\text { and dissemination }\end{array}$ & $\begin{array}{l}\text { The social mechanisms through which STEM professionals } \\
\text { review, evaluate and validate knowledge, for instance, } \\
\text { through the peer-review systems of journals }\end{array}$ \\
\hline Ethos & $\begin{array}{l}\text { The norms that STEM professionals employ in their work as } \\
\text { well as in interaction with colleagues }\end{array}$ \\
\hline Social values & $\begin{array}{l}\text { Values such as freedom, respect for the environment } \\
\text { and social utility }\end{array}$ \\
\hline Professional activities & $\begin{array}{l}\text { How STEM professionals engage in professional settings } \\
\text { such as attending conferences and doing publication reviews }\end{array}$ \\
\hline Social organisations and interactions & $\begin{array}{l}\text { How STEM is arranged in institutional settings such as } \\
\text { universities and research institutes }\end{array}$ \\
\hline Financial systems & $\begin{array}{l}\text { The underlying financial dimensions of STEM, including } \\
\text { funding mechanisms }\end{array}$ \\
\hline Political power structures & $\begin{array}{l}\text { The dynamics of power that exist between STEM } \\
\text { professionals and within disciplinary cultures }\end{array}$ \\
\hline
\end{tabular}

ethical norms, and when successful, ultimately produces knowledge and serves society. (Irzik and Nola 2014, p. 1014)

Diverse fields that belong to the umbrella of 'science', as in the case of 'game', cannot be defined based on sufficient and necessary conditions, but at best, resemble each other in terms of their cognitive and social aspects. Building on such pioneering work that introduced FRA as an alternative approach to NOS, Erduran and Dagher (2014a, b) proposed an extended version of FRA that consists of 11 categories. The authors not only unpacked these categories using philosophy of science literature but also they linked them to empirical work from research in science education highlighting the relevance for science education theory and practice. The categories have been adapted by Park et al. (in press) for the purpose of conceptualising nature of STEM disciplines (see Table 1). Their version encompasses the cognitive-epistemic NOS aspects (aims and values, methods, scientific practices, scientific knowledge) and social certification and dissemination, scientific ethos, social values and professional activities. An important aspect of Erduran and Dagher's FRA account is the use of visual representations to communicate some fairly deep ideas about NOS. The FRA wheel which summarises the entire approach consists of three embedded wheels (Fig. 1) which are intended to capture how science works in terms of its epistemic, cognitive, social and institutional dimensions. A review of the recent applications of FRA in science education is available in Erduran, Dagher and MacDonald (2019).

At the heart of the FRA framework is the recognition that, when one chooses any two disciplines under the umbrella of 'science', 'for any chosen pair of these sciences, one will be similar to the other with respect to some of these characteristics and dissimilar to one another with respect to other characteristics' (Irzik and Nola 2014). For example, astronomers and particle physicists commonly construct hypotheses, collect empirical data and interpret the 


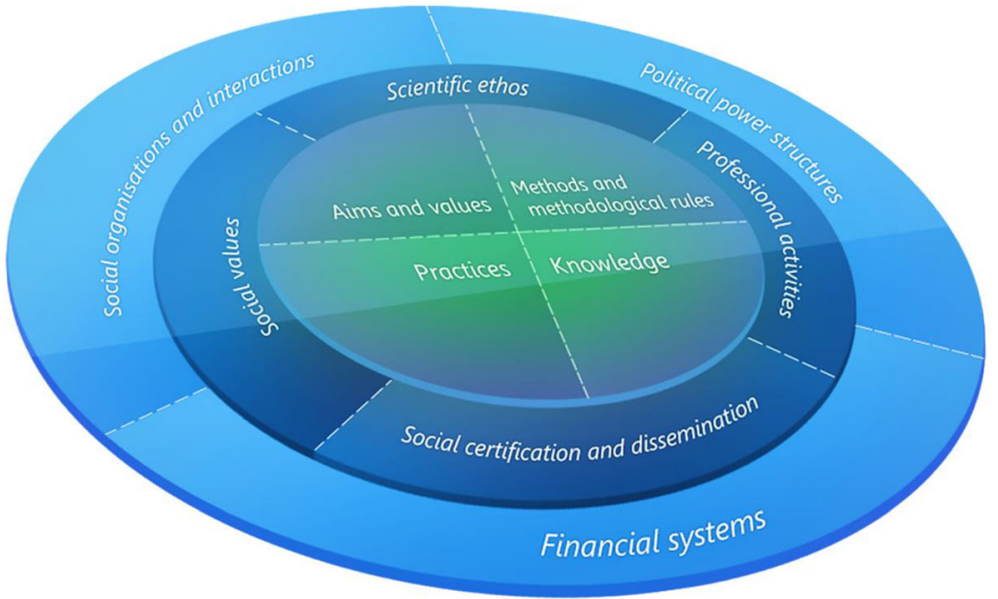

Fig. 1 FRA wheel: science as a cognitive-epistemic and social-institutional system (reprinted with permission from Erduran and Dagher 2014a, p. 28)

meaning of the data, but only the latter conduct laboratory experiments to test their hypotheses (Irzik and Nola 2014). On the other hand, when we compare particle physics to medical science, while they have common aspects (collecting data, making inferences and predictions), the latter features randomised controlled trial as a powerful method to draw conclusions about causal relationships, which particle physicists rarely do (Irzik and Nola 2014). This means that there is no clear set of necessary and sufficient conditions that defines the nature of science; rather, it is the numerous similarities between the sub-areas of science that hold the sciences together. The same account could be made for explaining STEM as a 'family' that comprises four members, each of whom resembles another in some aspects but where no two members are identical.

Although FRA was originally proposed as a conceptualisation of 'science', there are several characteristics of FRA that make it an adequate tool for analysing the nature of STEM disciplines. First, FRA highlights the similarity and dissimilarity in defining a concept. For this reason, when STEM disciplines are viewed through the lens of FRA, their epistemic nature can be understood in a more comparative and interconnected manner. For example, entrepreneurship, market and industry have traditionally been a main interest of technology rather than science, but this dichotomy is becoming increasingly obsolete today (Kaya et al. 2018). Patents are now considered as important as research papers in many areas of natural science, shattering the old conception that scientific knowledge are to be publicised and used for public goods instead of being kept to specific people for their economic profits (see Sect 7.1.3 of Erduran and Dagher 2014a, b). ${ }^{2}$ Similarly, comparing the core values pursued in science to those in technology, engineering and mathematics allows an understanding of the

\footnotetext{
${ }^{2}$ Irzik (2007) illustrated this point by drawing on the case of biomedical research in the USA to illustrate the changing culture of academic science in the wake of commercialisation and commodification of scientific knowledge. He noted that while 'basic science and technology were separate enterprises for a very long time', until they began to be blended in the nineteenth century. In his account, the emergence of 'technoscience' (e.g. computer science, information technology and genetic engineering) in the late twentieth century accelerated the blurring of the distinction between scientific knowledge and technological invention. For more on economics of science, see e.g., Erduran and Mugaloglu (2013) and Kaya et al. (2018).
} 
aims of science that is more sophisticated than when they are studied separately. These examples show that integrating technology, engineering and mathematics into science curricula does not only broadens the scope of science education, but also has the potential to deepen learners' understanding of NOS. Second, FRA provides a heuristic based on which the nature of diverse disciplines can be represented and investigated, rather than a set of declarative statements about the disciplines. For example, let us consider the fact that science and engineering both are bound by and interact with the wider society. When addressing this feature of science and engineering with students, it can be approached in several different ways (e.g. social values, social organisation and interaction, financial systems, political power systems), and FRA provides a useful lens to examine each at a deeper level.

The theoretical framework of FRA suggests that resemblances among STEM disciplines can be found with respect to the 11 categories of FRA (Erduran and Dagher 2014a, b). Hence, an analysis of standards documents should ideally take into account all categories in the FRA wheel (Fig. 1). However, such an analysis would require an extensive investigation which is beyond the scope of this paper. We focus on the aims, values and practices categories in three standards documents in this study because they were considered particularly important aspects of the documents and were also mentioned relatively frequently by the documents themselves. Table 2 presents the definitions and illustrative examples for the three categories that we focused on. There was a reasonable amount and breadth of data to be analysed with regard to these three categories, which allowed making qualitative comparisons both among the three countries and across the disciplines.

\section{Methods}

\subsection{The Context of Science Education Standards}

The main motivations for this study were to examine the potential of recent science education standards documents and thereby provide generalised implications for the treatment of nature of STEM disciplines beyond national boundaries. With this in mind, including NGSS for analysis was essential because of its wide influence not only across the USA but also around the globe. In addition to NGSS, we selected the science education standards documents from the East Asian countries of Korea and Taiwan, because international assessment schemes have shown them to be high-achievement countries in science and mathematics (OECD 2016; Song 2013; TIMSS and PIRLS International Study Centre 2015) and both have recently released new science education standards as long-term guidelines for curriculum development and instructional practice. Although the Next Generation Science Standards, the Korean Science Education Standards and Taiwanese Curriculum Guidelines of 12-Year Basic Education-Science all are intended to serve similar functions, their organisation and content vary because of the different philosophical bases of the documents and different practical needs across countries. Due to such variations, we expected that the comparative analysis of the three documents would enable an in-depth and rich examination of how each document represents the nature of STEM disciplines. In the following section, we briefly introduce the background to and organisation of each document in relation to nature of STEM disciplines. 
Table 2 Descriptions of each NOS aspect and illustrative examples from curriculum standards documents from the USA, Korea and Taiwan

\begin{tabular}{|c|c|c|}
\hline Category & Description & Illustrative examples \\
\hline Aims & $\begin{array}{l}\text { The outcomes that STEM professionals intend to } \\
\text { achieve as a result of their activities }\end{array}$ & $\begin{array}{l}\text {-Is the goal to answer a question? If so, students } \\
\text { are doing science. Is the purpose to define and } \\
\text { solve a problem? If so, students are doing } \\
\text { engineering. (NGSS, Appendix p. 49) } \\
\text {-The purpose of engineering investigations might } \\
\text { be to find out how to fix or improve the } \\
\text { functioning of a technological system or to } \\
\text { compare different solutions to see which best } \\
\text { solves a problem. (NGSS, Appendix p. 54) } \\
\text {-Science continues to advance the evolution of } \\
\text { civilisation. (CGBE-S, p. 5) }\end{array}$ \\
\hline Values & $\begin{array}{l}\text { The key epistemic and non-epistemic qualities } \\
\text { that STEM professionals commit to through- } \\
\text { out their activities }\end{array}$ & $\begin{array}{l}\text {-Each proposed solution results from a process of } \\
\text { balancing competing criteria of desired } \\
\text { functions, technical feasibility, cost, safety, } \\
\text { aesthetics and compliance with legal } \\
\text { requirements. (NGSS, p. 75) } \\
\text {-Understand the scientific values that distinguish } \\
\text { science from non-science, and understand the } \\
\text { relationship between science and other } \\
\text { disciplines ... (KSES, p. 69) } \\
\text {-Understand that scientists have some common } \\
\text { qualities, such as logical thinking, precision, } \\
\text { open-mindedness, objectivity, scepticism, } \\
\text { replicability, and honest and ethical reporting } \\
\text { of findings. (CGBE-S, p. 43) }\end{array}$ \\
\hline Practices & $\begin{array}{l}\text { The set of epistemic and cognitive practices that } \\
\text { lead to disciplinary knowledge through social } \\
\text { certification }\end{array}$ & $\begin{array}{l}\text {-Describe, measure, estimate, and/or graph quan- } \\
\text { tities (e.g. area, volume, weight, time) to ad- } \\
\text { dress scientific and engineering questions and } \\
\text { problems (NGSS, Appendix p. 59) } \\
\text {-Engineers continuously modify these systems to } \\
\text { increase benefits while decreasing costs and } \\
\text { risks. (NGSS, p. 110) } \\
\text {-Scientific investigation uses various methods } \\
\text { such as observation, data collection, analysis } \\
\text { and experimentation. (KSES, p. 69) } \\
\text { - Organise existing information or data by simple } \\
\text { classification, charting and so on. (CGBE-S, p. } \\
\text { 13) }\end{array}$ \\
\hline
\end{tabular}

\subsection{USA}

The NGSS was developed to be a set of research-based science content standards for many states in the USA. The standards incorporate three dimensions originally suggested in A Framework for K-12 Science Education: science and engineering practices, core disciplinary ideas and crosscutting concepts (NRC 2012). Aspects of NOS are highlighted in Appendices F and H and are often linked either to science and engineering practices or crosscutting concepts. In addition, some nature of STEM disciplines are addressed using connections with ideas within the disciplines of science and engineering and with the discipline of mathematics in the Common Core State Standards for English language arts and literacy in history/social studies, science and technical subjects (NGA and CCSSO 2010). In addition, some appendices focus on the relationships between science and the other three disciplines, such as references to the two sets of core ideas: 
'interdependence of science, engineering, and technology' and 'influence of engineering, technology, and science on society and the natural world'. Accordingly, both the main text of NGSS and the front and back matter (including appendices) were included in our analysis for 'aims' and 'values' categories. For the 'practices' category, we focused on Appendix F (science and engineering) and Appendix L (mathematics) as these were intended to explicate science engineering practices and mathematical practices that were present across the document.

\subsection{Korea}

Inspired by the release and subsequent implementation of NGSS, the Korean Ministry of Education (MOE) and the Korea Foundation for the Advancement of Science and Creativity started a series of science education initiatives. Science for All Koreans was published in 2016 and was followed by the publication of the Korean Science Education Standards (KSES) in 2019. KSES was developed by a team of educators with diverse backgrounds such as science educators, engineering educators, experts in language and global citizenship education, and curriculum theorists (MOE et al. 2019). Intended as a groundwork for the forthcoming national science curricula, classroom-level practices and out-of-school science education, KSES puts emphasis on the NOS and related aspects by listing 'nature of scientific knowledge and method', 'integration of science' and 'interaction between science and society' as its knowledge domains (MOE et al. 2019, p. 19, 60). ${ }^{3}$ The idea of STEAM ( $A$ for 'arts') was also taken seriously in the development of the standards, so KSES frequently states 'cross-subject integration' as a recommended instructional method for learning outcomes. The entire document including front and back matters were subjected to analysis.

\subsection{Taiwan}

The Curriculum Guidelines of 12-Year Basic Education-Science (CGBE-S) was developed as part of the wider curriculum reform in Taiwan (MOE 2018). The core literacy of science curriculum standards includes three domains: scientific core concepts, inquiry ability, and scientific attitude and nature of science, which are introduced in the rationale section, outlined in the core literacy section, elaborated in the learning performance and content section accordance with each grade level, and related with essential literacy. (Further information about science curriculum development on NOS in Taiwan is available in Yeh, Erduran and Hsu, 2019.). While each discipline has a comprehensive guideline in Taiwanese curriculum, we compared the guideline of science discipline with NGSS and KSES. In this study, we focused on the learning performance and content sections, and found supports in the rationale section to identify the descriptions of the nature of STEM disciplines.

\subsection{Document Analysis}

Although STEM is originally an acronym for four disciplines, we have chosen to take technology and engineering as a single field in our analysis. The decision not to treat them separately (e.g. Pleasants and Olson 2019) was made based on several theoretical and

\footnotetext{
${ }^{3}$ KSES and CGBE-S are written in Korean and Chinese (traditional), respectively. These documents sometimes provide English translations of their key terms, and we used these official translations in this paper when available. All other translations were made by the authors.
} 
practical considerations. Theoretically, the line between technology and engineering is often fluid in the education literature (e.g. ITEA/ITEEA 2007), as is that between NOT and NOE (e.g. de Vries 2003). For example, most chapters in the recently published Handbook of Technology Education (de Vries 2018) use the phrases 'technology education' and 'engineering education' interchangeably without precisely distinguishing between the two. In addition, given that our FRA analytical framework includes a wide range of elements that characterise a discipline, encompassing the process, products and social contexts, it was deemed more reasonable to consider technology and engineering as one broad field rather than two fields that can be compared with regard to their practices, social values and so on. For example, it would have been quite a challenge to judge whether statements in the standards documents such as 'to achieve the best possible design' refer to NOT or NOE.

Based on the descriptions of the 11 FRA categories (Table 1), the entire content of NGSS was reviewed by two coders independently to identify indicative statements of the nature of STEM disciplines. For example, the statement 'science investigations are guided by a set of values to ensure accuracy of measurements, observations, and objectivity of findings' (NGSS Lead States, Appendix H, p. 98) was identified as it aligned with the description of the values of science. We began by running an initial search based on the indicative keywords provided by Kaya and Erduran (2016). For example, search strings 'aim*' and 'goal*' were used to identify the references made to the aims category in FRA. Through this process, statements that actually describe the content of the aims (e.g. 'solve problems', 'improve systems') were found in the documents. Since these keywords could also be considered representations of the aims of STEM disciplines, a second round of searching was conducted with these new keywords. This second search was necessary because there often were statements relevant to the nature of a discipline but without explicit words such as 'aim', 'value' or 'practice'. The search results were then reviewed by the two researchers to ensure that the keywords actually referred to the FRA category and were not being used for other meanings (e.g. using 'aim' to refer to the aim of the standards document itself rather than of a discipline).

After these two rounds of document searches, the entire document was read multiple times to identify any references to the three FRA categories that were not explicitly covered in the previous searches. The lists of keywords in NGSS were generated by each coder and were compared to reach an agreement. To establish intercoder reliability, we had multiple discussions where detailed criteria for inclusion and exclusion were calibrated and could be applied consistently. These agreed-upon English keywords were then translated into Korean and Chinese by the authors who were native speakers of each language. The entire content of KSES and CGBE-S was searched using these translated keywords. The set of English keywords was then further refined by the two coders based on the results of the KSES and CGBE-S searches. The result of each search was summarised in a table by one coder and then were checked by the other to ensure reliability. It should be noted that repeated appearances of the same keyword in one document were not counted multiple times, because we were primarily interested in the coverage of each document in terms of an FRA category rather than frequency of appearance. Another consideration was that as curriculum standards, a structural feature of these documents is that many statements are repeated across multiple sections and different topics, so counting repetitions would not have added much value to the analysis. 


\subsection{Findings}

Overall, our analysis indicates that each of the three standards documents afforded different opportunities for addressing the nature of STEM disciplines and how they relate to each other. The nature of STEM disciplines was addressed in various parts of the documents such as the introduction and philosophy statement, expected learning outcomes, frameworks and assessment guidelines. Below we first describe how the aims, values and practices of STEM disciplines are represented in each document and then discuss how the three countries compare in terms of these categories.

In describing the results, we used Venn diagrams as a representational tool. This choice was based on the fact that they give a graphical summary of how each document addresses (or does not address) the target aspects, and that it is also consistent with the original idea of FRA which is based on set theory (Irzik and Nola 2011, 2014). In addition, they can highlight the similarities and differences between disciplines, which are a core interest of our study and align well with the philosophical assumption of FRA. Each Venn diagram has three overlapping circles representing science, technology/engineering and mathematics. Intersections indicate that an aspect was mentioned with regard to two or more disciplines. If, for example, 'objectivity' is included in the intersection of science and technology/engineering, either the document includes a single statement that refers to objectivity as a common value of science and technology or includes two statements that refer to the objectivity of science and technology separately. An aspect being listed only in a non-intersecting area of a discipline indicates that the document only addresses the aspect as a characteristic of that discipline.

\subsection{Aims of STEM Disciplines}

In this paper, we defined the aims of a discipline as the outcomes that professionals intend to achieve as a result of their activities. For what purposes do scientists, engineers and mathematicians do what they do? What are the aims shared across all STEM disciplines, and what are the ones specific to only some of them? Given that aims are one of the definitive features of a discipline, having a good sense of these questions will be a key to understanding the nature of STEM disciplines. Our analysis showed that all three documents included a range of descriptions of the aims of science, implying that the authors of the three standards documents considered them important for describing science. The aims of technology/engineering were also often mentioned to varying degrees in the three documents, sometimes in terms of how they relate or compare to the aims of science.

NGSS provided a rich description in terms of the aims, with the individual aims of science, engineering and mathematics all being covered to some extent (Fig. 2). The stated aims of science ranged from relatively abstract goals such as 'finding order' and 'advancing knowledge' to more concrete goals such as 'establishing evidence' and 'constructing theories'. The aims of engineering were also extensively addressed throughout the document. 'Defining and finding solutions to problems' appeared as a core engineering goal in several different contexts. Also, many goals related to design were presented, such as 'achieving the best design', 'designing causal systems' and 'improving/replacing technological systems'. More concrete goals were also stated, such as 'maximising certain types of energy output' and 'improving or replacing technologies'. What seemed more promising was that NGSS had statements that compared or contrasted the aims of science and 


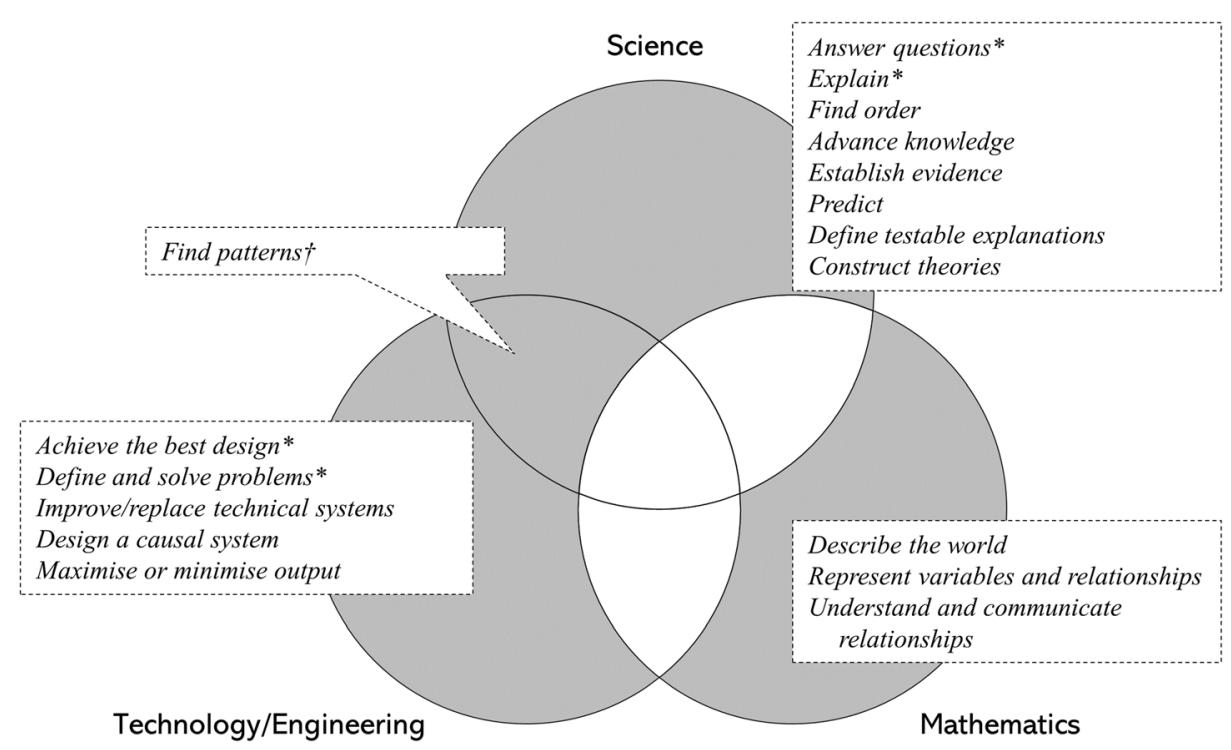

Fig. 2 Aims of STEM disciplines in NGSS (USA) ( $\uparrow:$ mentioned explicitly as a common feature across multiple disciplines; *: mentioned explicitly as a distinct feature of one discipline as opposed to another)

engineering. For example, 'finding patterns' was stated as a common goal of all fields of science and engineering, whereas the distinct aims of the two were also highlighted, as in the following statements: 'Is the goal to answer a question? If so, students are doing science. Is the purpose to define and solve a problem? If so, students are doing engineering' (Appendix p. 49); 'In engineering, the goal is a design rather than an explanation' ( $\mathrm{p}$. 52).

There were a few statements that indicated that the aims of mathematics were things such as 'describing the natural and designed worlds', 'representing variables and relationships' and 'understanding and communicating relationships'. These statements often read as the aims of mathematics in service of science and engineering rather than as its intrinsic aims as a discipline. Also, the aims of STEM disciplines in NGSS were mostly epistemic goals, and the social and environmental goals of science were not mentioned.

KSES referred to a number of aims specific to science (Fig. 3). These included 'understanding the diversity and complexity of nature', 'understanding change, stability and causality', 'describing things' and 'identifying problems in life'. When we compare these to the results from NGSS, we can see that KSES has a relative focus on science as a means of understanding and identifying the diverse aspects of nature, whereas NGSS has more descriptions of the active roles of humans such as constructing, explaining and predicting things.

One characteristic aspect of KSES was the frequent use of the term 'science and technology' throughout the document, making the overlap between the two more explicit than NGSS did. Such coupling of science and technology made an interesting comparison with NGSS (where 'science and engineering' was coupled to underscore common practices) and CGBE-S (which mostly only spoke about 'science'). In many places, KSES described the nature of 'science and technology' instead of that of 'science' alone, implying that the statement involves a common feature shared across the two disciplines. 


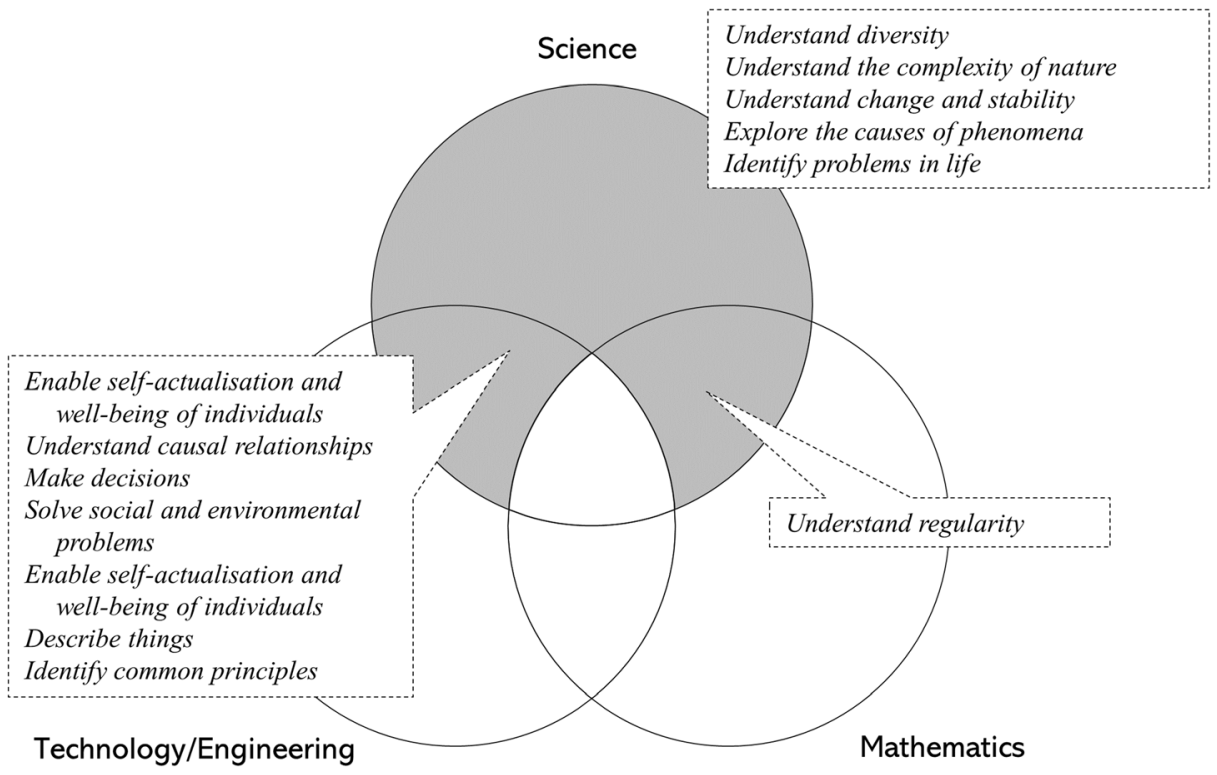

Fig. 3 Aims of STEM disciplines in KSES (Korea)

References to the aims of 'science and technology' included solving problems at diverse levels such as everyday lives, social problems and environmental problems.

Unlike NGSS, explicit descriptions of the relationship between STEM disciplines were not found in KSES. All statements indicated in the intersections were either made while describing science and technology as a whole (e.g. 'science and technology aim to ...') or area combination of two separate statements that pointed to the same aim (e.g. 'science

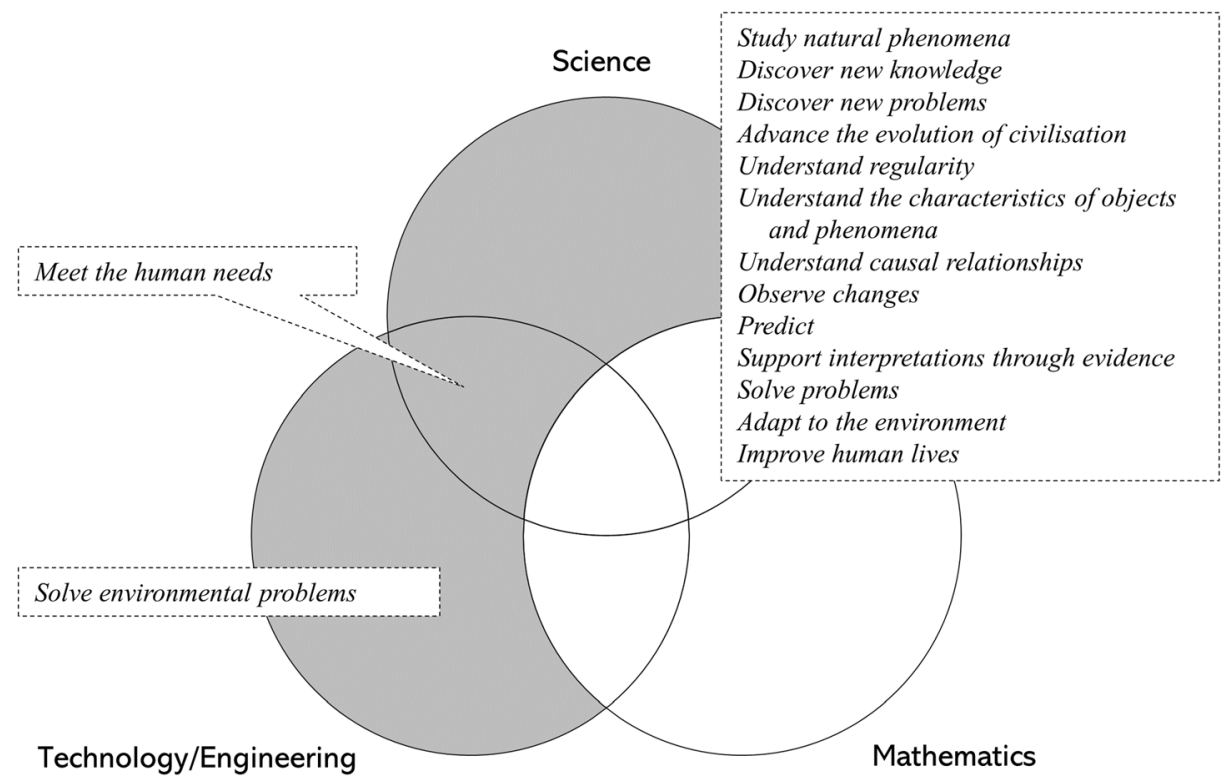

Fig. 4 Aims of STEM disciplines in CGBE-S (Taiwan) 
aims to understand regularity' and 'mathematics aims to understand regularity') at different places in the document. As a result, KSES was found to have an emphasis on aims specific to science and shared between science and other disciplines. No aims specific to engineering or mathematics were mentioned.

CGBE-S (Fig. 4) had a pattern similar to NGSS in terms of its depiction of the aims of science, including diverse goals that ranged from the abstract aims such as 'studying natural phenomena' and 'understanding regularity' to more practical and epistemic aims such as 'supporting interpretations using evidence'. It also addressed some engineering aims such as meeting the human needs, and solving social and environmental problems. Although CGBE-S provided rich descriptions of the aims of respective disciplines, there were no mentions made about the common or contrasting aims between STEM disciplines.

\subsection{Values in STEM Disciplines}

STEM professionals commit to various epistemic and non-epistemic values as they strive to achieve disciplinary aims. Epistemic values come into play when professionals conduct theoretical and empirical investigations and relate to the aim of producing reliable knowledge claims about the object of the investigation (Allchin 1999; Erduran and Dagher $2014 a, b)$. These values range from consistency, rationality, accuracy, objectivity and generality to more abstract values such as simplicity, unification and mathematical elegance (Park and Song 2019). Epistemic values are used as criteria for making choices between the competing hypotheses that account for the available observations equally well. At the same time, there is a range of non-epistemic values that influence professionals' practice, such as honesty and ethics. The divide between epistemic and nonepistemic values is oftentimes fluid and therefore artificial, because the social and cultural norms shared in the professional community are tightly coupled with the pursuit of epistemic values (Erduran and Dagher 2014a, b; Park and Song 2019). Overall, the three documents showed a significant amount of overlap in terms of their descriptions of disciplinary values, but also showed some differences in terms of which particular discipline each of these values was attributed to.

NGSS addressed several representative examples of values in science, such as accuracy, objectivity, scepticism and replicability, including more social and cultural values such as honesty and ethics (Fig. 5). Economic feasibility was mentioned as a value that engineers are conscious of during the design process. A great number of values appeared in the 'science and engineering practices' columns in NGSS. These values, coded as being common to both science and engineering, included validity, reliability, credibility, accuracy, technical feasibility, cost, safety, aesthetics and compliance with legal requirements. In the intersection of science and engineering, it should be noted that values such as 'technical feasibility' and 'compliance with legal requirements' are arguably taken more seriously by engineers than scientists due to the practical nature of the discipline (Bucciarelli 1994; Kroes 2012), although NGSS did not seem to explicitly address such a difference.

KSES, in addition to the well-known values of science such as reliability, credibility and rationality, addressed several interesting values that are not found in the other two documents (Fig. 6). While referring to what it calls 'scientific leadership', which was emphasised as a core quality of leaders in science and also scientifically literate citizens, KSES listed innovation, adventure, sensitivity to risks, agility, producing values, futuristic 

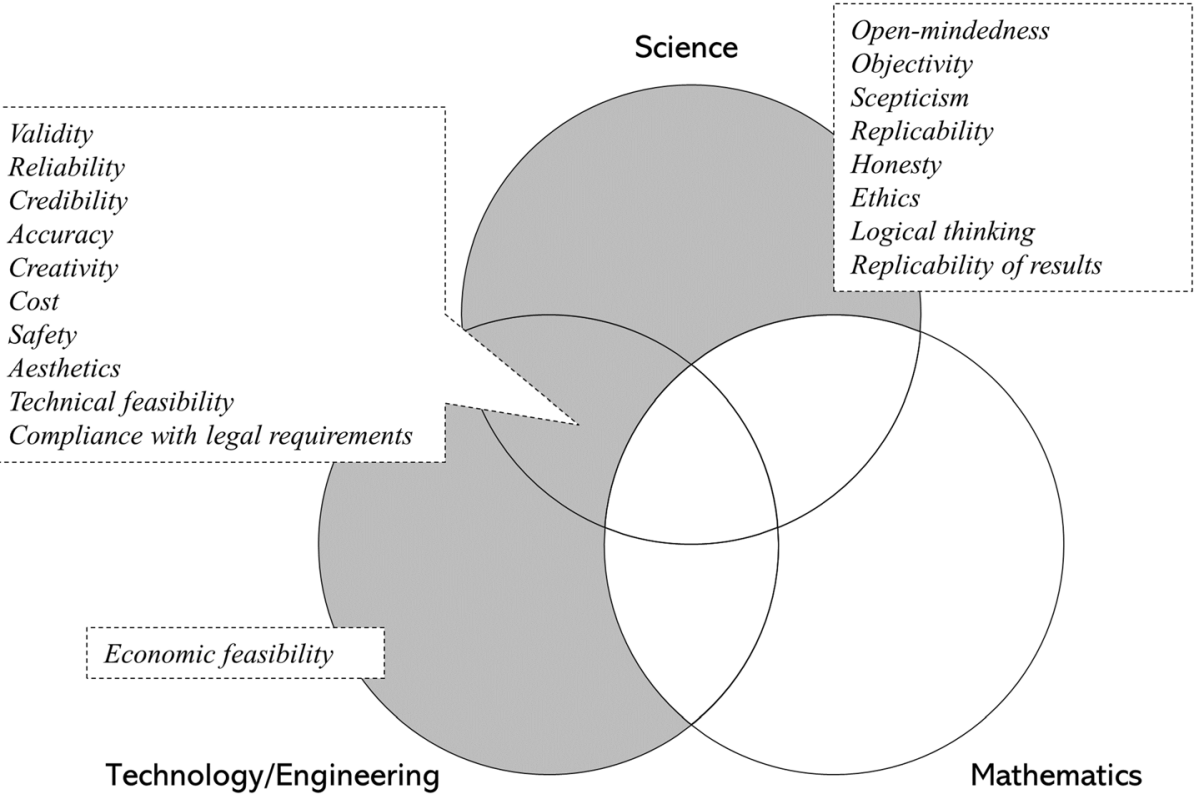

Fig. 5 Values in STEM disciplines in NGSS (USA)

attitude and risking challenges as the values that comprise scientific leadership. Along the same line, KSES referred to care and ethics as elements of scientific leadership. The relative emphasis of these social and cultural values in KSES can be understood in relation to the inclusion of 'participation and action' as one of the three core dimensions that

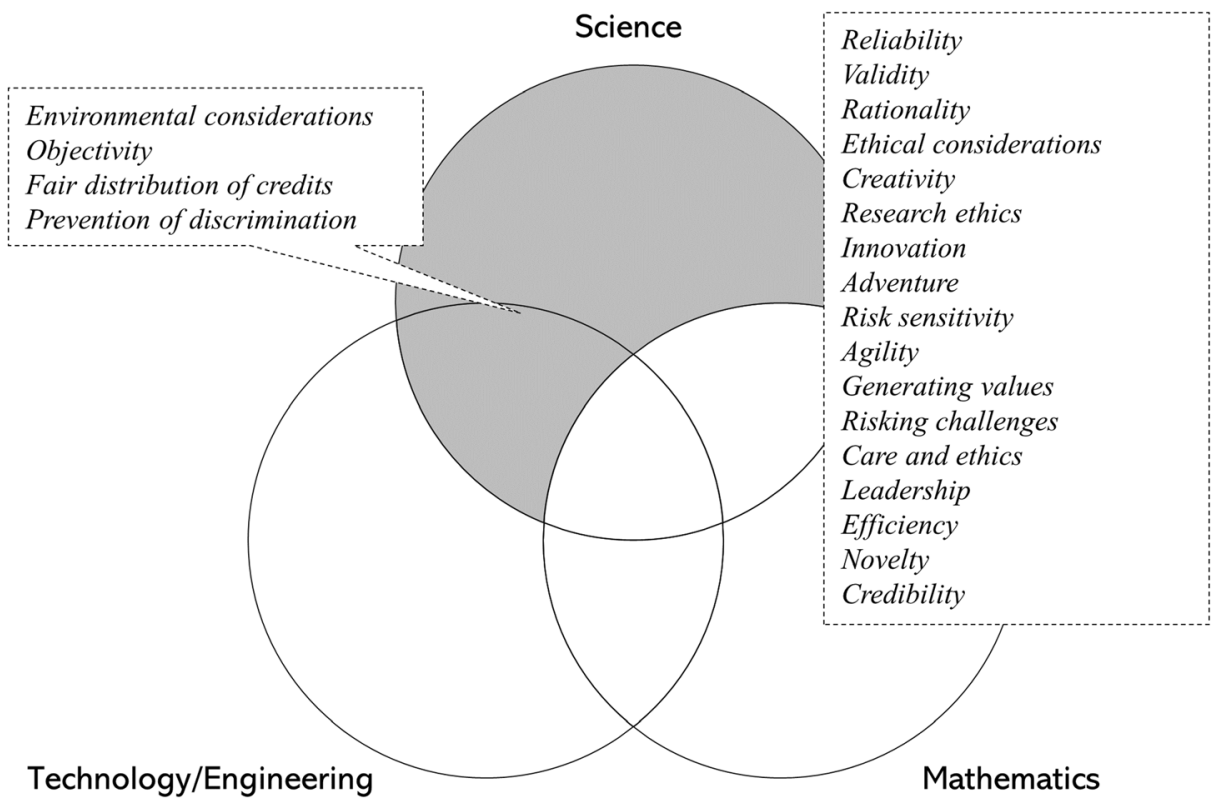

Fig. 6 Values in STEM disciplines in KSES (Korea) 
underpin the organisation of KSES (MOE et al. 2019). With the aim of 'promoting the participation in inquiry activities and application to real life', which has been 'particularly insufficient for Korean students' (p. 13), the participation and action dimension emphasises science community activities, scientific leadership, contribution to safe society, enjoying science culture, and contribution to a sustainable society. Such an emphasis explains at least in part the social values being addressed with regard to this core dimension.

As opposed to NGSS and KSES, in which several engineering values were mentioned, CGBE-S only addressed science values, but it revealed relatively diverse representation across the epistemic, social and cultural values that scientists commit to (Fig. 7). In particular, epistemic values such as logical thinking, accuracy and objectivity appeared multiple times in different places throughout the document. Below are some examples where CGBE-S referred to values in science.

The cognitive approach of science stresses empirical evidence, logic, scepticism and repeated review (p. 33)

Scientists have the qualities of perseverance, rigour, and logic (p. 22)

Understand the succinctness of scientific theory and the rigour of scientific thinking, and learn to appreciate the beauty of science (p. 43)

\subsection{Practices of STEM Disciplines}

Disciplinary practice in STEM refers to the set of epistemic and cognitive practices that lead to STEM knowledge through social certification (Table 1). Practice is an important component of

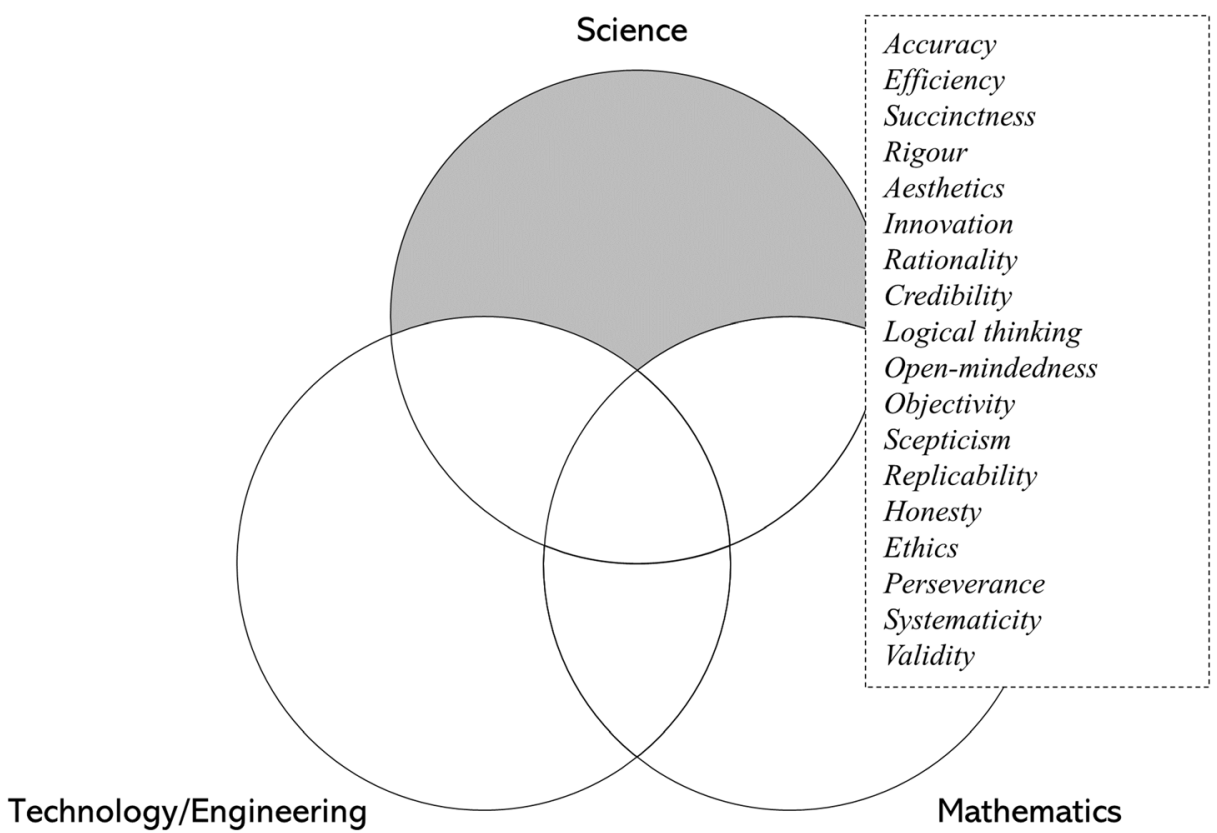

Fig. 7 Values in STEM disciplines in CGBE-S (Taiwan) 
STEM disciplines, which is gaining increasing attention in line with the shift of emphasis from 'science as knowledge' to 'science as practice' in science education (Erduran and Dagher 2014a) discussed three common examples of scientific practice: classification, observation and experimentation. These practices occur in 'a complex set of interactions including collection and analysis of data, and certification of subsequent knowledge claims' (p. 80). In technology and engineering, there are practices shared with science, such as modelling, but some others clearly matter more for engineers, such as optimisation and prototyping of design. With regard to mathematical practices, Science for All Americans (AAAS 1989) emphasises abstraction, symbolic representation and manipulation of mathematical statements as common practices that mathematicians regularly engage in. Since the connection to the empirical world is relatively weak in mathematics, it is unsurprising that its core practices also have some features that are distinguished from those of science and engineering. The representation of STEM practices in the three analysed documents showed diverse practices across disciplines, but at the same time revealed limitations similar to those involving values in STEM.

In NGSS, argumentation and reasoning, interpreting data, using tools, measurement, working with numbers, ratios, representations, models and units were mentioned as common practices across the three disciplines. NGSS also addressed diverse practices shared by science and engineering (Fig. 8), which was predictable given its emphasis of 'science and engineering practice'. It encompassed the practices for gathering first-hand data (e.g. observation, experimentation), processing and interpreting data (e.g. statistical analysis, comparison and contrast), and representing and sharing the results of scientific and engineering activities (e.g. simulation, communicating information and design ideas). In addition, NGSS often compared and contrasted scientific practices and engineering practices. For example, it distinguishes constructing explanations and designing solutions, and describe each as a core practice of science and engineering, respectively. The following paragraph delineates how design as an engineering practice is distinct from scientists' activities to develop an explanation:

The process of developing a design is iterative and systematic, as is the process of developing an explanation or a theory in science. Engineers' activities, however, have elements that are distinct from those of scientists. These elements include specifying constraints and criteria for desired qualities of the solution, developing a design plan, producing and testing models or prototypes, selecting among alternative design features to optimise the achievement of design criteria, and refining design ideas based on the performance of a prototype or simulation. (NRC 2012, pp. 68-69; quoted in NGSS Appendix, p. 60)

In Appendix L, NGSS explicates the connections between NGSS and the Common Core State Standards for Mathematics (NGACBP and CCSSO 2010) by illustrating how mathematical practices are relevant to science standards. ${ }^{4}$ A range of mathematical practices that are relevant to science and engineering were mentioned, as seen in the boxes on the right in Fig. 8. In particular, NGSS made an explicit remark on the similarities and differences between argumentation in science and mathematics:

\footnotetext{
${ }^{4}$ The Common Core State Standards for Mathematics describes eight mathematical practices: Make sense of problems and persevere in solving them, reason abstractly and quantitatively, construct viable arguments and critique the reasoning of others, model with mathematics, use appropriate tools strategically, attend to precision, look for and make use of structure and look for and express regularity in repeated reasoning (NGACBP and CCSSO 2010).
} 


\begin{tabular}{|c|c|c|}
\hline $\begin{array}{l}\text { Communicating information or } \\
\quad \text { design ideas } \\
\text { Working with texts and imagest } \\
\text { Recording information } \\
\text { Evaluating data } \\
\text { Statistical analysis } \\
\text { Comparison and contrast } \\
\text { Representation } \\
\text { Observation } \\
\text { Experimentation } \\
\text { Controlling variables } \\
\text { Prediction } \\
\text { Testing and refining design } \\
\text { Using and developing simulations } \\
\text { Organising and searching data } \\
\text { Creating and using algorithms } \\
\text { Computational thinking } \\
\qquad \quad \text { Designing solutions* } \\
\quad \text { Defining problems* } \\
\text { Technology/Engineering }\end{array}$ & $\begin{array}{l}\text { Constructing explanations* } \\
\text { Asking questions* }\end{array}$ & $\begin{array}{l}\text { Argumentation and reasoning }{ }^{\dagger} \\
\text { Interpreting data } \\
\text { Using tools } \\
\text { Measurement } \\
\text { Developing and using models } \\
\text { Working with ratios and } \\
\quad \text { proportional relationships } \\
\text { Working with representations } \\
\text { Working with numbers and } \\
\quad \text { quantities } \\
\text { Using and converting units }\end{array}$ \\
\hline
\end{tabular}

Fig. 8 Practices of STEM disciplines in NGSS (USA)

[As mathematics,] science too involves making arguments and critiquing them. However, there is a difference between mathematical arguments and scientific arguments- $\mathrm{a}$ difference so fundamental that it would be misleading to connect any of the standards to MP.3. here. The difference is that scientific arguments are always based on evidence, whereas mathematical arguments never are. It is this difference that renders the findings of science provisional and the findings of mathematics eternal. Blurring the distinction between mathematical and scientific arguments leads to a

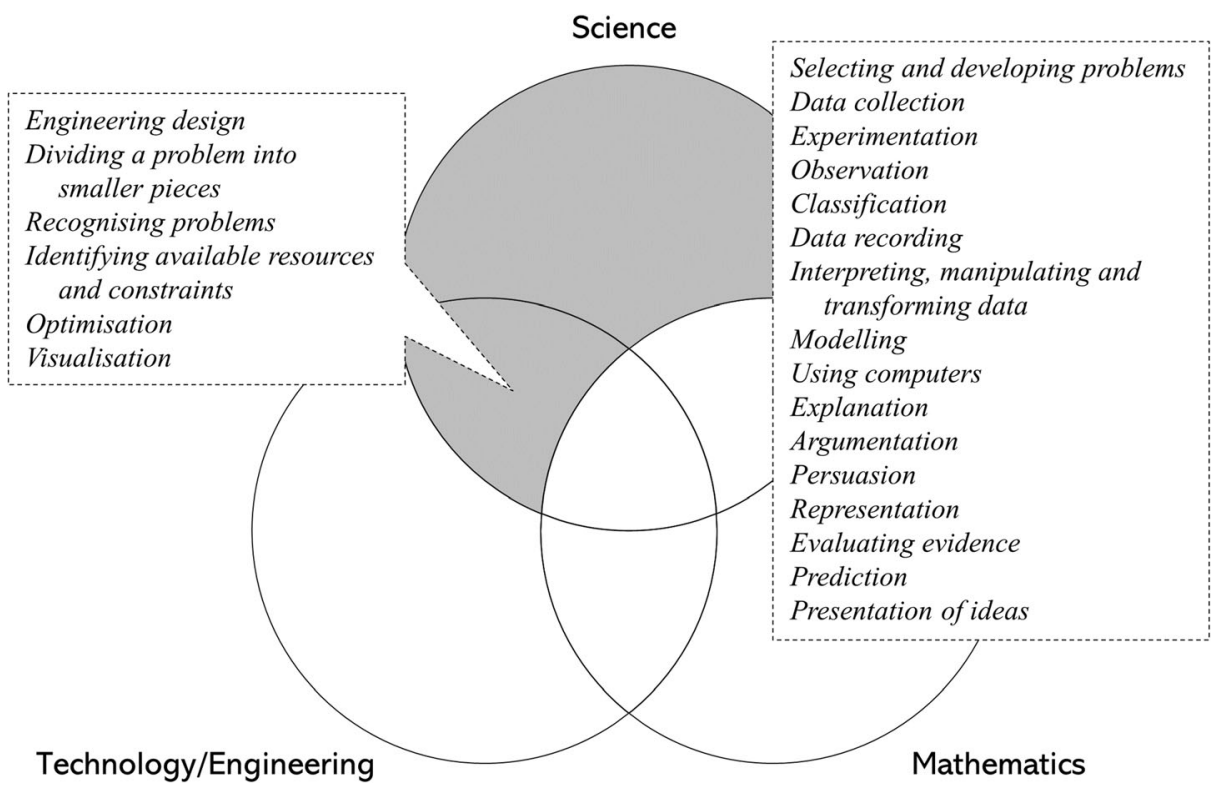

Fig. 9 Practices of STEM disciplines in KSES (Korea) 
misunderstanding of what science is about. For more information about argumentation in science, see the NGSS science and engineering practice 'Engaging in argument from evidence'. (Appendix p. 140)

KSES addressed many practices specific to science, without particularly referring to their relationship to practices of other disciplines (Fig. 9). Various practices were mentioned from the conception of problems (e.g. 'selecting and developing problems') and processes of inquiry (e.g. 'experimentation', 'classification', 'modelling') to the dissemination and sharing of knowledge (e.g. 'representation', 'presentation of ideas'). KSES interestingly defined 'engineering design ability' as a component of scientific thinking skills. Engineering design ability encompasses 'dividing a problem into smaller pieces', 'recognising problems', 'identifying available resources and constraints', 'optimisation' and 'visualisation', which were interpreted as common practices across science and engineering. No practices related to mathematics were addressed in the document.

CGBE-S presented an extensive amount and variety of scientific practices throughout the document. These practices spanned across almost all stages of scientific investigation from questioning to constructing arguments and presenting results (Fig. 10). In particular, there were some standards that specified an advanced level of epistemic understanding of scientific practice. For example, the standard 'based on the experimental results, reflect on the advantages and disadvantages of the experimental process to correct experimental models or innovative breakthroughs' (p. 9) involves an elaborated view of scientific experimentation that encourages students to reflect on the affordances and limits of the process. Similarly, another standard, 'reasonably predict the likely outcome of the activity and the possible causes for failure' (p. 32), requires students to recognise the limitations of a research design along with its expected results. With regard to reasoning and argumentation, CGBE-S emphasised using multiple methods of reasoning, stating that '[students] can use a combination of

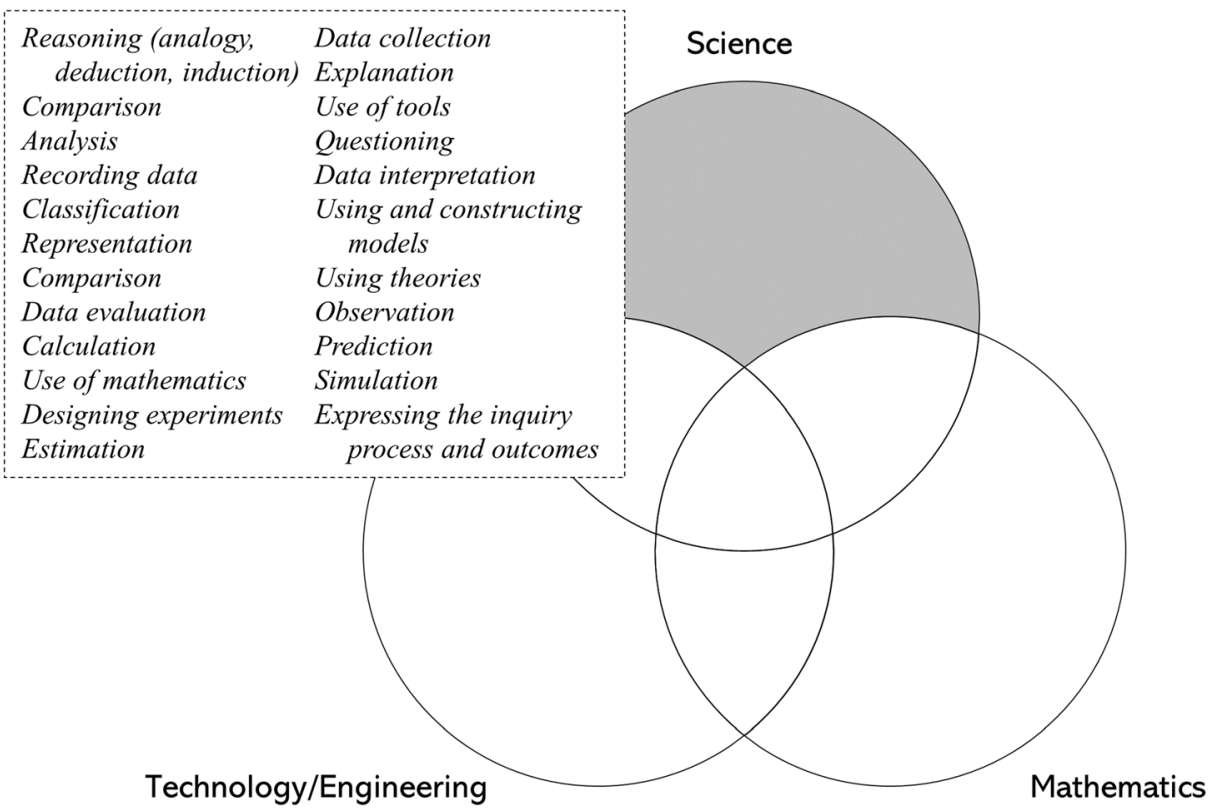

Fig. 10 Practices of STEM disciplines in CGBE-S (Taiwan) 
scientific evidence and theories, as well as analogy, transformation and other deductive reasoning' (p. 42). However, as was true for the values category, CGBE-S made no mention of engineering and mathematical practices.

\subsection{Cross-Country Comparison}

The main findings are summarised in Table 3. The occurrence of instances is represented for each category and do not consider the frequency count of reference. This is because we were more interested in whether or not each aspect was mentioned in the documents, not how often they were mentioned. In the three documents, features specific to science and shared by science and engineering were most frequently addressed. In NGSS and KSES, the commonalities between science and engineering (technology) were mentioned across all three FRA categories, implying that this overlap is emphasised in these documents. Particularly in NGSS, engineering-related aspects were widely covered. Mathematics-related features were most evidently covered in NGSS, whereas in other documents, they were rarely addressed. This means that the similarities and differences between science and mathematics as academic and professional disciplines and how the two relate to and rely on each other is not given sufficient attention that they merit.

As seen from the table, NGSS covered relatively many aspects of STEM among the three documents. Whereas NGSS had a wide coverage across the aims, values and practices of STEM disciplines, it tended to address the epistemic aspects of STEM rather than the social. Compared to NGSS, KSES and CGBE-S did not include as many descriptions about the nature of technology, engineering and mathematics. KSES frequently mentioned the common aspects of science and technology, but as in NGSS, the differences between science and technology were rarely represented overall. CGBE-S stated diverse aims across disciplines, but when it comes to values and practices, it did not make any attempts at engineering or mathematics. Some of these cross-country differences can be attributed to the different emphases of each standards document. The emphasis on 'science and engineering practices' in NGSS explains the relative abundance of statements that belong to the intersection of science and engineering and, to a degree, also explains the absence of science- and engineering-specific practices. Also, as mentioned earlier, KSES's focus on 'participation and action' and STEAM (defined broadly to include arts and humanities) seemed to be relevant to the inclusion of many social, cultural and environmental values of science and engineering.

Table 3 Coverage of nature of STEM disciplines in NGSS, KSES and CGBE-S

\begin{tabular}{|c|c|c|c|c|c|c|c|c|}
\hline & & \multicolumn{3}{|c|}{ Specific to one discipline } & \multicolumn{3}{|c|}{ Shared between two disciplines } & \multirow{2}{*}{$\begin{array}{l}\text { Shared among three } \\
\text { disciplines } \\
\text { S\&TE\&M }\end{array}$} \\
\hline & & $\mathrm{S}$ & $\mathrm{TE}$ & M & S\&TE & TE\&M & $\mathrm{S} \& \mathrm{M}$ & \\
\hline \multirow[t]{3}{*}{ NGSS } & Aims & $X$ & $X$ & $X$ & $\mathrm{X}$ & & & \\
\hline & Values & $\mathrm{X}$ & $X$ & & $\mathrm{X}$ & & & \\
\hline & Practices & $X$ & $X$ & $X$ & $\mathrm{X}$ & & & $X$ \\
\hline \multirow[t]{3}{*}{ KSES } & Aims & $X$ & & & $\mathrm{X}$ & & $X$ & \\
\hline & Values & $X$ & & & $\mathrm{X}$ & & & \\
\hline & Practices & $X$ & & & $\mathrm{X}$ & & & \\
\hline \multirow{3}{*}{ CGBE-S } & Aims & $X$ & $X$ & & $\mathrm{X}$ & & & \\
\hline & Values & $X$ & & & & & & \\
\hline & Practices & $X$ & & & & & & \\
\hline
\end{tabular}

$S$ science, $T E$ technology and engineering, $M$ mathematics 


\section{Discussion}

In this paper, we presented a systemic analysis of how science education standards documents represent the nature of STEM disciplines. In doing so, we used standards documents from three different countries, which allowed a rich understanding of each document to a deeper level. However, it is important to note that our analysis was not meant to evaluate or rank the standards documents. Considering that the nature of STEM disciplines is an underexplored territory, it would be unrealistic to expect that the standards documents have a sophisticated view on this matter and address diverse aspects of STEM. Also, since we did not 'score' the documents nor did we count the occurrences, the results should not be interpreted as representing the quality of standards documents. Rather, our primary purpose for comparison was to shed light on the relative strengths and weaknesses of each document that would not have made visible when only one document was considered. Besides their differences, the three documents as a whole provided several observations for science educators to integrate NOS, NOTE and NOM as well as STEM in future curricula and standards.

The analysis of the curriculum standards documents from the USA, Korea and Taiwan illustrated what epistemic aims, values and practices are mentioned specifically. The systematic study in the coverage of these components of the standards provides information of how different curriculum standards compare and which particular features they emphasise. The findings illustrate that there is diversity in the way that epistemic aims, values and practices are discussed in these documents. Furthermore, they indicate what emphasis each document places on different aspects. Despite the structural differences among the documents, at least two important common themes were identified across the three countries. The first was the general underrepresentation of mathematics in the standards documents. What distinct aims mathematics has that differ from those of empirical sciences, what practices mathematicians regularly engage in and how those practices helps achieve the aims of science are very rarely addressed in the analysed documents. The second theme, particularly evident in NGSS and KSES, was the overemphasis of science-engineering intersection, which seemed to have resulted in science-specific aims, values and practices being hidden in the standards. In both documents, the similarities between science and engineering were represented more evidently than their differences. This seemed to have led to downplaying the subtle nuances that distinguish the two disciplines and may give a misleading impression that science and engineering are essentially the same. To prevent this, standards documents need to be more explicit about what makes science 'science'.

We have used the FRA framework to investigate curriculum documents in relation to STEM. Although FRA has previously been used for such purposes, for instance in the analysis of science curriculum documents from Turkey (Kaya and Erduran 2016), Taiwan (Yeh et al. 2019) and Ireland (Erduran and Dagher 2014b) as well as science textbooks (Park and Song, 2019; Park et al. 2020; McDonald 2017), the current study adopted the framework to be used in the context of STEM related standards in science curricula. We acknowledge that the FRA framework was originally developed within the context of NOS in order to show the similarities and differences across different scientific disciplines. We rationalised its use in STEM because the FRA categories produced by Erduran and Dagher (2014a) are fairly broad and can potentially capture both the disciplinary similarities as well as the differences between science, technology, engineering and mathematics. For example, mathematics and science can be quite different in their specific aims and values, but the category of 'aims and values' itself is what enables us to examine what these differences might be. 
Overall, then, we had a pragmatic approach in utilising the FRA as a coding tool in order to make comparative sense of curriculum standards related to STEM disciplines. In other words, our use of FRA is about applying FRA categories as analytical tools for empirical purposes, and hence, limited inferences should be drawn about the theoretical underpinnings of the applications of FRA in relation to science, technology, engineering and mathematics. Our approach was based on the assumption that it the notion of STEM education already presupposes some proximity among the four disciplines, potentially allowing us to consider them as 'family members' from an FRA perspective. A fully justified theoretical account can be pursued in due course by other researchers to embellish the conceptual value of using FRA in the characterisation of STEM.

We should note that our adaptation of FRA categories as coding tools for characterising STEM related standards in science curriculum documents does not necessarily imply that technology, engineering and mathematics are to be approached from a scientific lens. However, our focus is on science education and hence, the choice of science curriculum documents is a given considering our purpose of the study which was to conduct a comparative science curriculum analysis internationally. While the broad definitions of the FRA categories were used to trace the narrative on technology, engineering and mathematics, none of the specific features of the science-related FRA categories were imposed on the curriculum statements about technology, engineering and mathematics. For instance, when NGSS made reference to 'economic feasibility' as a value that engineers are conscious of during the design process, our starting point in capturing this code was the key reference to engineering, not science. Indeed, explicit references to 'science', 'technology', 'engineering' and 'mathematics' was a decisive criterion on tracing the documents so as to avoid unwarranted inferences and biasing of the categories through the lens of science.

As we mentioned earlier, proper understanding of NOTE and NOM is not only valuable educational aims by themselves, but also is of particular importance for a nuanced and contextualised understanding of NOS. When students learn about the practices of science, they should not only engage in the scientific practice themselves but also be encouraged to reflect on whether that practice is a definitive feature of science relative to other disciplines, how it compares to similar practices in other disciplines and how it contributes to achieving the aims and values of scientists. Once this is done in a developmentally appropriate manner, we believe, students will acquire a more sophisticated understanding of NOS than when it is taught independently of other fields. While the precursor to such an idea in science education is found in Science for All Americans (AAAS 1989) published 20 years ago (see Sect 2.2), our analysis showed that the recent science education standards documents generally lack a structured approach to the nature of STEM disciplines. This calls for curriculum designers to pay attention to the intersection of NOS and STEM, and dedicate efforts to make connections between NOS and STEM in the science education standards documents.

Methodologically, we elaborated on the concept of family resemblance as a lens to look at the nature of STEM disciplines. In general, our study suggested that FRA can be used as a lens to reveal the emphases and omissions of standards documents in terms of the nature of STEM disciplines, which merit curriculum designers' attention to the development of future science education standards and curricula. The 'heuristic' nature of the FRA framework (Erduran and Dagher 2014a, b) allows understanding NOS, NOTE and NOM using a single coherent framework, rather than treating them separately and making separate lists of features to describe each discipline. By focusing on the 'resemblances' that encompass similarities and differences among disciplines, this approach affords a nuanced description of STEM as a 
family that consists of different members. In a similar way that we recognise how the members of a family resembles each other, students can learn about what are the features that connect STEM as well as how they differ from each other in terms of their epistemic and social aspects. We believe that our analysis of the three standards documents provided initial but useful clues that should inform the implementation of NOS instruction and STEM integration based on these documents. The missing connections among STEM should be made explicit during the curriculum and assessment design, and classroom implementations. While the present study focused on science education standards, future cross-disciplinary efforts will be necessary to align these standards with technology and mathematics education standards so that they can create synergy to better understand STEM within the school curriculum.

\section{Compliance with Ethical Standards}

Conflict of Interest The authors declare that they have no conflict of interest.

Open Access This article is licensed under a Creative Commons Attribution 4.0 International License, which permits use, sharing, adaptation, distribution and reproduction in any medium or format, as long as you give appropriate credit to the original author(s) and the source, provide a link to the Creative Commons licence, and indicate if changes were made. The images or other third party material in this article are included in the article's Creative Commons licence, unless indicated otherwise in a credit line to the material. If material is not included in the article's Creative Commons licence and your intended use is not permitted by statutory regulation or exceeds the permitted use, you will need to obtain permission directly from the copyright holder. To view a copy of this licence, visit http://creativecommons.org/licenses/by/4.0/.

\section{References}

\section{Standards Documents}

NGSS Lead States. (2013). Next generation science standards: for States, by States. Washington: National Academy Press.

Ministry of Education (MOE). (2018). Curriculum guidelines of 12-year basic education: science. Taipei: MOE. Ministry of Education (MOE), Ministry of Science and ICT (MSICT), \& Korea Foundation for the Advancement of Science and Creativity (KOFAC). (2019). Scientific literacy for all Koreans: Korean science education standards for the next generation. Seoul: KOFAC.

Secondary Literature

Abd-El-khalick, F., \& Lederman, N. G. (2000). Improving science teachers' conceptions of nature of science: a critical review of the literature. International Journal of Science Education, 22(7), 665-701.

Abd-El-Khalick, F., Waters, M., \& Le, A. P. (2008). Representations of nature of science in high school chemistry textbooks over the past four decades. Journal of Research in Science Teaching, 45(7), 835-855.

Akerson, V. L., Abd-El-Khalick, F., \& Lederman, N. G. (2000). Influence of a reflective explicit activity-based approach on elementary teachers' conceptions of nature of science. Journal of Research in Science Teaching, 37(4), 295-317.

Allchin, D. (1999). Values in science: an educational perspective. Science \& Education, 8(1), 1-12.

Allchin, D. (2017). Beyond the consensus view: whole science. Canadian Journal of Science, Mathematics and Technology Education, 17(1), 18-26.

American Association for the Advancement of Science. (1989). Science for all Americans. Washington: Author. Antink-Meyer, A., \& Brown, R. A. (2019). Nature of engineering knowledge: an articulation for science learners with nature of science understandings. Science \& Education, 28(3-5), 539-559. 
Association of American Colleges and Universities. (AACU). (2013). It takes more than a major: Employer priorities for college learning and student success. Available at www.aacu.org/leap/documents/2013 EmployerSurvey.pdf. Retrieved January 21, 2014.

Bucciarelli, L. (1994). Designing engineers. Cambridge: MIT Press.

Bybee, R. W. (2013). The case for STEM education: challenges and opportunities. Arlington: NSTA Press.

Carnevale, A. P., Smith, N., \& Melton, M. (2011). STEM: Science Technology Engineering Mathematics. Georgetown University Center on Education and the Workforce.

Charette, R. N. (2014). STEM sense and nonsense. Educational Leadership, 72(4), 79-93.

Chesky, N. Z., \& Wolfmeyer, M. R. (2015). Philosophy of STEM education: a critical investigation. New York: Palgrave Macmillan.

Chiappetta, E.L., Ganesh, T.G., Lee, Y.H., \& Phillips, M.C. (2006). Examination of science textbook analysis research conducted on textbooks published over the past 100 years in the United States. Paper presented at the annual meeting of the National Association for Research in Science Teaching, San Francisco, CA.

Dagher, Z. R., \& Erduran, S. (2017). Abandoning patchwork approaches to nature of science in science education. Canadian Journal of Science, Mathematics and Technology Education, 17(1), 46-52.

De Vries, M. J. (2003). The nature of technological knowledge: extending empirically informed studies into what engineers know. Techné, 7(3), 1-12.

De Vries, M. J. (2018). Handbook of technology education. Cham: Springer.

Duschl, R. A., \& Bismack, A. S. (2016). Reconceptualizing STEM education: the central role of practices. London: Routledge.

Engelmann, K., Chinn, C. A., Osborne, J., \& Fischer, F. (2018). The roles of domain-specific and domaingeneral knowledge in scientific reasoning and argumentation. In F. Fischer, C. A. Chinn, K. Engelmann, \& J. Osborne (Eds.), Scientific reasoning and argumentation: The roles of domain-specific and domaingeneral knowledge (pp. 1-8). London: Routledge.

Erduran, S., \& Dagher, Z. R. (2014a). Reconceptualizing the nature of science for science education: scientific knowledge, practices and other family categories.. Dordrecht: Springer.

Erduran, S., \& Dagher, Z. R. (2014b). Regaining focus in Irish junior cycle science: Potential new directions for curriculum and assessment on Nature of Science. Irish Educational Studies, 33(4), 335-350.

Erduran, S., Dagher, Z., \& MacDonald, C. (2019). Contributions of the Family Resemblance Approach to nature of science in science education: a review of emergent research and development. Science \& Education, 28(35), pp.311-328.

Erduran, S., \& Mugaloglu, E. Z. (2013). Interactions of economics of science and science education: Investigating the implications for science teaching and learning. Science \& Education, 22(10), 2405-2425.

Forinash, K., Rumsey, W., \& Lang, C. (2000). Galileo's mathematical language of nature. Science \& Education, 9(5), 449-457.

Gendron, B. (1977). Technology and the human condition. New York: St Martin's Press.

Haag, S., \& Megowan, C. (2015). Next generation science standards: a national mixed-methods study on teacher readiness. School Science and Mathematics, 115(8), 416-426.

Hodson, D. (2014). Nature of science in the science curriculum: origin, development, implications and shifting emphases. In M. R. Matthews (Ed.), International handbook of research in history, philosophy and science teaching (pp. 911-970). Dordrecht: Springer.

Hodson, D., \& Wong, S. L. (2017). Going beyond the consensus view: broadening and enriching the scope of NOS-oriented curricula. Canadian Journal of Science, Mathematics and Technology Education, 17(1), 317.

Honey, M., Pearson, G., \& Schweingruber, H. (2014). STEM integration in K-12 education. Washington: National Academy Press and National Research Council.

Irzik, G. (2007). Commercialization of science in a neoliberal world. In A. Buğra \& K. Ağartan (Eds.), Reading Karl Polanyi for the twenty-first century: market economy as a political project (pp. 135-153). London: Palgrave.

Irzik, G., \& Nola, R. (2011). A family resemblance approach to the nature of science for science education. Science \& Education, 20(7-8), 591-607.

Irzik, G., \& Nola, R. (2014). New directions for nature of science research. In M. R. Matthews (Ed.), International handbook of research in history, philosophy and science teaching (pp. 999-1021). Dordrecht: Springer.

ITEA/ITEEA (2007). Standards for technological literacy. Retrieved from www.iteea. org/TAA/PDFs/ListingofSTLContentStandards.pdf. Accessed 10 October 2019.

Janich, P. (1978). Physics - natural science or technology? In W. Krohn, E. T. Layton Jr., \& P. Weingart (Eds.), The dynamics of science and technology: social values, technical norms and scientific criteria in the development of knowledge (pp. 3-27). Dordrecht: Springer. 
Kaya, E., \& Erduran, S. (2016). From FRA to RFN, or how the Family Resemblance Approach can be transformed for science curriculum analysis on nature of science. Science \& Education, 25(9-10), 11151133 .

Kaya, S., Erduran, S., Birdthistle, N., \& McCormack, O. (2018). Looking at the social aspects of nature of science in science education through a new lens: The role of economics and entrepreneurship. Science \& Education, 27(5-6), 457-478.

Kroes, P. (2012). Technical artefacts: creations of mind and matter: a philosophy of engineering design. Dordrecht: Springer.

Lederman, N. G. (2007). Nature of science: past, present, and future. In S. K. Abell \& N. G. Lederman (Eds.), Handbook of research on science education (pp. 831-880). Mahwah: Erlbaum.

Lederman, N. G., \& Lederman, J. S. (2017). The Next Generation Science Standards: implications for science teacher education. [Special Issue]. Journal of Science Teacher Education, 25(2).

Lederman, N. G., Abd-El-Khalick, F., Bell, R. L., \& Schwartz, R. S. (2002). Views of nature of science questionnaire: toward valid and meaningful assessment of learners' conceptions of nature of science. Journal of Research in Science Teaching, 39(6), 497-521.

Lee, M.-H., Wu, Y.-T., \& Tsai, C.-C. (2009). Research Trends in Science Education from 2003 to 2007: a content analysis of publications in selected journals. International Journal of Science Education, 31(15), 1999-2020.

Lin, T.-C., Lin, T.-J., \& Tsai, C.-C. (2014). Research Trends in Science Education from 2008 to 2012: a systematic content analysis of publications in selected journals. International Journal of Science Education, 36(8), 1346-1372.

Lin, T.-C., Lin, T.-J., Potvin, P., \& Tsai, C.-C. (2018). Research trends in science education from 2013 to 2017: a systematic content analysis of publications in selected journals. International Journal of Science Education, 36(8), 1346-1372.

Martín-Páez, T., Aguilera, D., Perales-Palacios, F. J., \& Vílchez-González, J. M. (2019). What are we talking about when we talk about STEM education? A review of literature. Science Education, 103(4), 799-822.

Matthews, M. R. (2012). Changing the focus: from nature of science (NOS) to features of science (FOS). In M. S. Khine (Ed.), Advances in nature of science research: concepts and methodologies (pp. 3-26). Dordrecht: Springer.

McComas, W. F., \& Olson, J. K. (2002). The nature of science in international science education standards documents. In W. F. McComas (Ed.), The nature of science in science education (pp. 41-52). Springer.

McDonald, C. V. (2017). Exploring representations of nature of science in Australian junior secondary school science textbooks: A case study of Genetics. In C. V. McDonald (Ed.), Representations of nature of science in school science textbooks: A global perspective (pp. 98-117). London: Routledge.

McComas, W. F., Clough, M. P., \& Almazroa, H. (1998). The role and character of the nature of science in science education. In W. F. McComas (Ed.), The nature of science in science education: rationales and strategies (pp. 3-39). Dordrecht: Kluwer.

Merrill, C. (2009). The future of TE masters' degrees: STEM. Louisville: Paper presented at the meeting of the International Technology Education Association.

National Governors Association Center for Best Practices (NGACBP), \& Council of Chief State School Officers (CCSSO). (2010). Common core state standards for mathematics. Washington: NGACBP \& CCSSO.

National Research Council. (1996). National science education standards. Washington: National Academy Press.

National Research Council. (2012). A framework for K-12 science education: practices, crosscutting concepts, and core ideas. Washington: The National Academy Press.

OECD. (2016). PISA 2015 results (volume I): excellence and equity in education. Paris: PISA, OECD Publishing Retrieved 1 October 2019 from https://www.oecd-ilibrary.org/education/pisa-2015-results-volumei 9789264266490 -en.

Olson, J. K. (2018). The inclusion of the nature of science in nine recent international science education standards documents. Science \& Education, 27(7-8), 637-660.

Pacey, A. (1983). The culture of technology. Cambridge: MIT Press.

Park, W., \& Song, J. (2019). Between realism and constructivism: A sketch of pluralism for science education. In E. Herring, K. Jones, K. Kiprijanov, \& L. Sellers (Eds.), The past, present and future of integrated history and philosophy of science (pp. 228-247). London: Routledge.

Park, W., Yang, S., \& Song, J. (2019). When modern physics meets nature of science: The representation of nature of science in general relativity in new Korean physics textbooks. Science \& Education, 28(9-10), 1055-1083.

Park, W., Wu, J.-Y., \& Erduran, S. (in press). Investigating the epistemic nature of STEM: Analysis of curriculum documents from the USA using the Family Resemblance Approach. In Anderson, J., \& Li, Y. (Eds.) Integrated approaches to STEM education: An international perspective. Dordrecht: Springer. 
Park, W., Yang, S., \& Song, J. (2020). Eliciting students' understanding of nature of science with text-based tasks: Insights from new Korean high school textbooks. International Journal of Science Education, 42(3), $426-450$.

Pitt, J. C. (2000). Thinking about technology: foundations of the philosophy of technology. New York: Seven Bridges Press.

Pleasants, J., \& Olson, J. K. (2018). What is engineering? Elaborating the nature of engineering for K-12 education. Science Education, 103(1), 145-166.

Pleasants, J., \& Olson, J. K. (2019). What is engineering? Elaborating the nature of engineering for K-12 education. Science Education, 103(1), 145-166.

Price, D. S. (1984). The science/technology relationship, the craft of experimental science, and policy for the improvement of high technology innovation. Research Policy, 13(1), 3-20.

Sadler, T. D., \& Brown, D. E. (2018). A critical examination of the next generation science standards. [Special Issue]. Journal of Research in Science Teaching, 55(7).

Song, J. (2013). The disparity between achievement and engagement in students' science learning: a case of EastAsian regions. In D. Corrigan, R. Gunstone, \& A. Jones (Eds.), Valuing assessment in science education: pedagogy, curriculum, policy (pp. 285-306). Dordrecht: Springer Netherlands.

STEM Task Force Report. (2014). Innovate: A blueprint for science, technology, engineering, and mathematics in California public education. Dublin: Californians Dedicated to Education Foundation.

Summers, R., Alameh, S., Brunner, J., Maddux, J. M., Wallon, R. C., \& Abd-El-Khalick, F. (2019). Representations of nature of science in U.S. science standards: a historical account with contemporary implications. Journal of Research in Science Teaching, 56(9), 1234-1268.

TIMSS \& PIRLS International Study Center (2015). TIMSS 2015 international reports. Retrieved 1 October 2019 from http://timss2015.org/timss-2015/science/student-achievement/

Wilson, M. R., \& Bertenthal, M. W. (2005). Systems for state science assessment. Washington, DC: The National Academy Press.

Williams, P. J. (2011). STEM education: proceed with caution. Design and Technology Education, 16(1), 26-35.

Wong, V., Dillon, J., \& King, H. (2016). STEM in England: meanings and motivations in the policy arena. International Journal of Science Education, 38(15), 2346-2366.

Yacoubian, H., \& Hansson, L. (in press) (Eds.). Nature of science for social justice. Dordrecht: Springer.

Yeh, Y., Erduran, S., \& Hsu, Y. S. (2019). Investigating coherence on nature of science in the science curriculum documents: Taiwan as a case study, Science \& Education, 28(3-5), pp. 291-310. https://doi.org/10.1007 /s11191-019-00053-1

Zeidler, D. L. (2016). STEM education: a deficit framework for the twenty first century? A sociocultural socioscientific response. Cultural Studies of Science Education, 11(1), 11-26.

Publisher's Note Springer Nature remains neutral with regard to jurisdictional claims in published maps and institutional affiliations. 